\title{
Erratum to: Bacterial brown spot on Avena storigosa Schereb. caused by Pseudomonas syringae pv. alisalensis
}

\author{
Yoshiyuki Ishiyama $\cdot$ Naho Yamagishi $\cdot$ \\ Hideki Ogiso - Masashi Fujinaga - Fuyumi Takahashi • \\ Yuichi Takikawa
}

Published online: 25 July 2013

(C) The Phytopathological Society of Japan and Springer Japan 2013

\section{Erratum to: J Gen Plant Pathol (2013) 79:155-157 DOI 10.1007/s10327-013-0427-9}

The authors would like to apologize for these errors.

The author's names should be as follows:

"Yoshiyuki Ishiyama · Naho Yamagishi · Hideki Ogiso · Masashi Fujinaga · Fuyumi Takahashi · Yuichi Takikawa"

The address of Fuyumi Takahashi and Yuichi Takikawa should be as follows.

"F. Takahashi · Y. Takikawa

Graduate School of Agriculture, and Graduate School of Science and Technology, Shizuoka University, Shizuoka 422-8529, Japan"

On page 156, line 10 in left column:

"P. stringae pv. alisalensis KB211" should be "P. syringae pv. alisalensis KB211".
On page 156, Table 1, line 1 in column 5 and page 157, Table 2, line 1 in column 5:

"P. s. pv. coronafaciens AVPCO8101" should be "P. s. pv. coronafaciens SUPP196 (AVPCO8101)".

On page 157, line 8-9 in Figure legend 2:

"P. syringae pv. coronafaciens AVPCO8101" should be "P. syringae pv. coronafaciens SUPP196 (AVPCO8101)".

On page 156, Table 1, line 1 in column 6 and page 157, Table 2 , line 1 in column 6 :

"P. s. pv. striafaciens AVPCO8101" should be "P. s. pv. striafaciens SUPP110 (avena2)".

On page 157, line 9-10 in Figure legend 2:

"P. syringae pv. striafaciens SUPP101" should be " $P$. syringae pv. striafaciens SUPP110 (avena2)".

The online version of the original article can be found under doi:10.1007/s10327-013-0427-9.

Y. Ishiyama $(\bowtie) \cdot$ N. Yamagishi $\cdot$ M. Fujinaga

Nagano Vegetable and Ornamental Crops Experiment Station,

So-ga Tokoo, Shiojiri, Nagano 399-6461, Japan

e-mail: ishiyama-yoshiyuki-r@pref.nagano.lg.jp

H. Ogiso

Nagano Vegetable and Ornamental Crops Experiment Station,

Saku-Branch, Yamaura, Komoro, Nagano 384-0807, Japan

F. Takahashi $\cdot$ Y. Takikawa

Graduate School of Agriculture, and Graduate School of Science

and Technology, Shizuoka University, Shizuoka 422-8529,

Japan 